\title{
Iron Deficiency Anemia in Infancy Is Associated with Altered Temporal Organization of Sleep States in Childhood
}

\author{
PATRICIO D. PEIRANO, CECILIA R. ALGARÍN, MARCELO I. GARRIDO, AND BETSY LOZOFF
}

Sleep Laboratory [P.D.P., C.R.A., M.I.G.], Institute of Nutrition and Food Technology (INTA), University of Chile, Macul, Santiago 7830489, Chile; Department of Pediatrics and Communicable Diseases [B.L.], Center for Human Growth and Development, University of Michigan, Ann Arbor, Michigan 48109

\begin{abstract}
The highest prevalence of iron deficiency anemia (IDA) in infancy coincides with a time of rapid changes in sleep organization. Since IDA in infancy is associated with long-lasting neurofunctional effects despite iron treatment, the normal development of sleep patterns might be affected. Night polysomnographic recordings were performed in 55 healthy 4 -y-old children (former IDA $=27$, nonanemic controls $=28$ ). Both groups were followed from infancy and were similar in background characteristics. The duration of each waking episode was measured, as was the duration of each episode of nonrapid eye movement (NREM) sleep stages 1 (NREM1), 2 (NREM2), and 3-4 (SWS), and rapid eye movement (REM) sleep. The data were analyzed according to the successive thirds of the total sleep time (TST). Relative to controls, former IDA children showed: a) longer duration of REM sleep episodes in the first third and shorter in the last third; b) more REM sleep episodes in the first third and fewer in the second third; and c) shorter latency to the first REM sleep episode and shorter NREM stage 2 and SWS episodes within the first sleep cycle. The results show that early IDA is associated with long-lasting alterations in the temporal organization of sleep patterns. (Pediatr Res 62: 715-719, 2007)
\end{abstract}

$\mathrm{T}$ his study considered the long-lasting impact of iron deficiency anemia (IDA) in infancy on the organization of sleep states. Iron deficiency - the most common preventable nutritional deficiency in the world and a major cause of anemia-is associated with alterations in development and behavior, particularly during infancy and toddlerhood when there is rapid growth and high need for iron $(1,2)$. We previously reported that infants with IDA showed alterations in sensory pathway functioning and motor activity patterns, with some differences persisting despite timely correction of anemia with carefully supervised iron therapy (3-6). Other studies find poorer mental, motor, and social-emotional functioning in IDA infants, again with differences observed years after iron treatment $(2,7)$. Additionally, animal studies show that rodents that experience early iron deficiency also have persisting behavioral differences related to motor function, learning and memory, and emotional responses $(2,8,9)$.

The quality and quantity of sleep are increasingly recognized as important factors in human development, with con-

Received March 19, 2007; accepted July 25, 2007.

Correspondence: Patricio D. Peirano, M.D., Ph.D., Sleep Laboratory, INTA, University of Chile, P.O. Box 138-11, Santiago, 7830489 Chile; e-mail: ppeirano@inta.cl

Supported by grants from the National Institutes of Health, Bethesda, MD (R01 HD33487 to BL) and the Chilean Agency for Funding in Science and Technology (CONICYT, Fondecyt 1040945 to PP). comitant effects on affective behavior and cognitive performance $(10,11)$. The organization of sleep depends on various mechanisms involving both neural and humoral processes, several of which are affected by iron deficiency. In rodent models, early iron deficiency impairs several neurotransmitter systems, myelin formation and maintenance, and metabolic neuronal activity $(8,12)$. When iron deficiency occurs during central nervous system (CNS) development in infancy, changes in several functions are not completely reversed with iron therapy at weaning $(2,8,9,12)$.

Because iron deficiency in human infants is most prevalent during the latter part of the brain growth spurt, the normal development of sleep patterns could be particularly affected. To the best of our knowledge, no human or nonhuman primate studies have evaluated the lasting effects of early IDA on sleep organization. Moreover, in rodent models the only related aspect studied has been spontaneous motor activity $(8,9,13-15)$, without assessing sleep-wake patterns or long-term effects on sleeprelated issues. We report here a study of sleep organization in a group of Chilean preschool children who either had IDA or were nonanemic in infancy. We predicted that IDA in infancy would be associated with altered sleep organization even several years after iron therapy.

\section{METHODS}

Subjects. The children in this study are participants in ongoing research in Chile on the behavioral, developmental, neurosensory, cognitive, and sleepwake pattern effects of IDA in infancy. Detailed descriptions of the population and findings during infancy have been published elsewhere (1,3-6). In brief, study participants were healthy full-term infants (birth weights $\geq 3.0 \mathrm{~kg}$, no perinatal complications, and no acute or chronic illnesses). Infants were assessed for IDA at 6,12 , and 18 mo. Anemia was defined as venous $\mathrm{Hb} \leq$ $100 \mathrm{~g} / \mathrm{L}$ at $6 \mathrm{mo}$ and $<110 \mathrm{~g} / \mathrm{L}$ at 12 and $18 \mathrm{mo}$ (for details see ref. 1). Iron deficiency was defined as two of three iron measures in the iron-deficient range [mean cell volume $<70 \mathrm{fL}$, erythrocyte protoporphyrin $>100 \mu \mathrm{g} / \mathrm{dL}$ red blood cells $(1.77 \mu \mathrm{M})$, serum ferritin $<12 \mu \mathrm{g} / \mathrm{L}]$. For each IDA infant, an infant of the same age who was clearly nonanemic (venous $\mathrm{Hb} \geq 115 \mathrm{~g} / \mathrm{L}$ ) was randomly selected. They constituted the "control" group. Six-month-old infants were treated for one year with $15 \mathrm{mg} / \mathrm{d}$ of elemental iron as oral ferrous sulphate; infants identified at 12 or 18 mo were treated with oral iron $(30 \mathrm{mg} / \mathrm{d})$ for a minimum of $6 \mathrm{mo}$. To assure that infants from the control

\footnotetext{
Abbreviations: DA, dopamine; IDA, iron deficiency anemia or iron-deficient anemic; NREM, non-rapid eye movement; NREM1, non-rapid eye movement sleep stage 1; NREM2, non-rapid eye movement sleep stage 2; REM, rapid eye movement; SPT, sleep period time; SWS, non-rapid eye movement sleep stages 3 and 4; TST, total sleep time; WASO, wakefulness after sleep onset
} 
group did not develop IDA with advancing age, they underwent the same iron treatment.

As part of a preschool-age follow-up, we conducted sleep-wake studies for children who had IDA in infancy (former IDA) or were nonanemic controls and were healthy and not taking any medications at the time of polysomnographic recording: 27 former IDA and 28 controls, at a mean age of $3.9 \mathrm{y}$. Table 1 shows the background characteristics of the groups. There were no statistically significant differences in child or family factors.

The research protocol was approved by the Institutional Review Boards of the University of Michigan Medical Center, Ann Arbor, the Instituto de Nutrición y Tecnología de los Alimentos (INTA), University of Chile, Santiago, and the Office of Protection from Research Risks, National Institutes of Health. Signed informed consent was obtained from the parent(s) or guardian.

Procedures. All sleep measures were acquired and processed without knowledge of whether a given child was former IDA or control. The wake-up time and the length of the waking episode that preceded the night recording were estimated from information provided by the mother.

Polygraphic recordings were conducted in the sleep laboratory of INTA, University of Chile, in a special quiet and comfortable room during the children's spontaneous night sleep, under naturally occurring sleep-wake cycles. The procedures were standardized to limit the potential influences of ambient environment, circadian rhythms, and/or food intake on sleep-waking patterns and related physiologic activities. Children and their mothers were transported from home to the laboratory so that they arrived at least one hour before their usual dinnertime. Upon arrival, mothers and child had the opportunity to become familiar with personnel and setting, while playing or relaxing. They then ate dinner together and engaged in their own routines before the child's bedtime. Electrodes were attached according to usual procedures. Children wore their own sleepwear. The ambient temperature was maintained constant $\left(20-22^{\circ} \mathrm{C}\right)$ throughout the recording session. Mothers also stayed in the lab overnight, sleeping in a nearby room after the child fell asleep.

Recording was done continuously on a TECA 1A97 18-channel polygraph (TECA, Corp., Pleasantville, NY) with a speed of $30 \mathrm{~mm} / \mathrm{s}$ as follows: EEG, with electrode placement adapted from the international 10-20 system; rapid eye movements, monitored by electrooculogram; tonic chin and diaphragmatic electromyograms using surface electrodes; motor activity of both upper and lower limbs recorded independently by piezo-electric crystal transducers; abdominal respiratory movements using a mercury strain gauge; nostril airflow by a thermistor; and ECG using surface electrodes. Skin temperature and oximetry were also recorded. All data were simultaneously recorded on

Table 1. Background characteristics*

\begin{tabular}{lcc}
\hline \multicolumn{1}{c}{ Group } & Former IDA & $\begin{array}{c}\text { Nonanemic } \\
\text { controls }\end{array}$ \\
\hline Total $n$ & 27 & 28 \\
Child & & \\
Age at preschool follow-up (y) & $3.9 \pm 0.6$ & $3.9 \pm 0.5$ \\
$\quad$ Gender [\% male $(n)$ ] & $74 \%(20)$ & $57 \%(16)$ \\
Gestational age (wk) & $39.3 \pm 1.0$ & $39.3 \pm 1.0$ \\
Birth weight (kg) & $3.43 \pm 0.39$ & $3.51 \pm 0.42$ \\
Birth length (cm) & $50.4 \pm 2.4$ & $50.5 \pm 1.7$ \\
Growth in infancy (12 mo) & & \\
$\quad$ Weight-for-age $z$-score & $-0.03 \pm 0.89$ & $-0.14 \pm 0.85$ \\
$\quad$ Height-for-age $z$-score & $0.01 \pm 0.88$ & $-0.15 \pm 0.94$ \\
Iron status at study entry in infancy§ & & \\
$\quad$ Hemoglobin (g/L) & $101.3 \pm 7.9$ & $124.4 \pm 6.8$ \\
$\quad$ Mean corpuscular volume (fL) & $67.0 \pm 4.5$ & $75.5 \pm 2.3$ \\
$\quad$ Erythrocyte protoporphyrin & $181.9 \pm 100.9$ & $79.6 \pm 21.3$ \\
$\quad$ ( $\mu$ g/dL RBC) & & \\
$\quad$ Ferritin ( $\mu \mathrm{g} / \mathrm{L})$ & $5.9 \pm 5.8$ & $17.2 \pm 11.2$ \\
Family & & \\
Socioeconomic status index & $27.3 \pm 6.7$ & $27.6 \pm 5.9$ \\
HOME score in infancy & $30.3 \pm 4.5$ & $30.4 \pm 3.5$ \\
Father's education (y) & $10.1 \pm 2.4$ & $10.2 \pm 2.0$ \\
Mother's education (y) & $10.0 \pm 2.3$ & $9.6 \pm 3.2$ \\
\hline
\end{tabular}

* Values are means \pm SD for continuous variables and percentages $(n)$ for categorical variables. Statistical significance was determined by the $t$ test or $\chi^{2}$.

$\S$ There were no significant differences except for hematologic status in infancy. By design, iron status at study entry in infancy was different between groups, with statistical significance on all iron measures $(p<0.0001)$. paper and computer, converted on-line from analog-to-digital signals, collected on hard drive, and then transferred to compact disks for off-line analyses. Child behavior was also observed directly and noted on the polygraphic paper.

Coding waking and sleep states. Waking and sleep states were coded visually by the temporal concordance of EEG, electrooculogram, and tonic chin electromyogram criteria according to accepted international standards (16). The minimum length of a state was $1 \mathrm{~min}$. Interruption of the concordance between the given parameters for $1 \mathrm{~min}$ or more was considered as an interruption of the state; shorter changes were included in the preceding state. Two independent scorers analyzed all recordings visually without knowledge of group membership, and inter-scorer reliability was determined for sleepwaking stages. Kappa for inter-scorer agreement was 0.96 [95\% confidence interval (CI): 0.957 to 0.962 ]. Scoring discrepancies were discussed and codes thus agreed upon were used in the data analysis. The duration of each waking episode was measured, as was the duration of each episode of nonrapid eye movement (NREM) sleep stages 1 (NREM1), 2 (NREM2) and 3-4 (SWS), and rapid eye movement (REM) sleep. The data were analyzed according to the successive thirds of the total sleep time (TST).

The following conventional sleep-wake parameters were evaluated; times are in minutes:

- Sleep onset latency: time from lights out to sleep onset, defined as the first minute of NREM1 or any other stage

- SPT: time from sleep onset to sleep end

- TST: the time from sleep onset to the end of the final sleep epoch minus time awake

- Sleep efficiency: the percentage ratio between TST and SPT (TST/ SPT*100)

- WASO: the time spent awake between sleep onset and end of sleep

- Total duration and percentage of NREM1, NREM 2, SWS, and REM sleep

- REM latency: time from sleep onset to the onset of the first REM episode

Statistical analysis. For continuous and normally distributed variables, differences between the former IDA and control groups were tested with use of $t$ test. The Folded form of the $F$ statistic was computed to test for equality of variance. If variances were found to be unequal, an approximate $t$ was calculated and degrees of freedom were corrected using Satterthwaite's method. Variables that showed significant departure from normality because of skewness were evaluated using the nonparametric Mann-Whitney $U$ test for medians. The distribution of categorical variables was examined with Fisher's exact test or $\chi^{2}$ tests. Analyses of covariance with age and sex as covariates were conducted. All statistical tests were two-sided and the level of significance $(\alpha)$ was set at 0.05 . Statistical analysis used Statistica version 7.0 for Windows (StatSoft, Inc., Tulsa, OK).

\section{RESULTS}

Conventional sleep-wake parameters, REM sleep, and NREM sleep stages percentage, episode number, and episode duration for each third of the TST, as well as first sleep cycle features, are shown in Table 2.

Waking and overall sleep. The total amount of waking throughout the day/night period (prior waking + intrasleep waking) was similar between groups. However, the duration of the daytime waking episode was longer in former IDA children $(p<0.03)$, and the amount of WASO was slightly greater in the control group due to episodes that lasted longer in the first third of the night $(p<0.05)$. Sleep latency, SPT, TST, and sleep efficiency were similar in both groups of

Table 2. Conventional sleep-wake parameters

\begin{tabular}{lccc}
\hline & \multicolumn{3}{c}{ Nonanemic } \\
& Former IDA & controls & $p$ value \\
\hline Sleep latency (min) & $20 \pm 18$ & $18 \pm 14$ & NS \\
SPT (min) & $515 \pm 88$ & $502 \pm 97$ & NS \\
TST (min) & $477 \pm 83$ & $449 \pm 85$ & NS \\
Sleep efficiency (\%) & $93.0 \pm 6.1$ & $90.0 \pm 9.9$ & NS \\
Diurnal waking duration (h) & $14.5 \pm 1.3$ & $13.7 \pm 1.3$ & $<0.03$ \\
\hline
\end{tabular}

$*$ Values are means $\pm \mathrm{SD}$ 
Table 3. REM sleep and NREM sleep stages (\% of TST) for each third of the TST

\begin{tabular}{crrr}
\hline & Former IDA & $\begin{array}{c}\text { Nonanemic } \\
\text { controls }\end{array}$ & $p$ value \\
\hline First third & & & \\
NREM1 & $2.5 \pm 3.3$ & $2.0 \pm 1.5$ & $\mathrm{NS}$ \\
NREM2 & $15.4 \pm 4.3$ & $15.2 \pm 5.6$ & $\mathrm{NS}$ \\
SWS & $15.7 \pm 5.9$ & $17.2 \pm 6.0$ & $\mathrm{NS}$ \\
REM & $3.1 \pm 2.4$ & $1.3 \pm 1.8$ & $<0.006$ \\
Second third & & & \\
NREM1 & $1.8 \pm 1.9$ & $1.4 \pm 1.8$ & $\mathrm{NS}$ \\
NREM2 & $18.5 \pm 6.7$ & $16.9 \pm 6.9$ & $\mathrm{NS}$ \\
SWS & $4.0 \pm 3.3$ & $4.8 \pm 3.4$ & $\mathrm{NS}$ \\
REM & $6.5 \pm 2.8$ & $7.1 \pm 3.4$ & $\mathrm{NS}$ \\
Third third & & & \\
NREM1 & $2.3 \pm 2.8$ & $1.2 \pm 2.1$ & $\mathrm{NS}$ \\
NREM2 & $20.0 \pm 6.9$ & $18.5 \pm 7.0$ & $\mathrm{NS}$ \\
SWS & $3.2 \pm 3.8$ & $4.4 \pm 4.4$ & $\mathrm{NS}$ \\
REM & $6.9 \pm 2.8$ & $9.8 \pm 4.0$ & $<0.002$ \\
\hline
\end{tabular}

* Values are means $\pm \mathrm{SD}$.

Table 4. REM sleep and NREM sleep stages episode number for each third of the TST

\begin{tabular}{cccc}
\hline & Former IDA & $\begin{array}{c}\text { Nonanemic } \\
\text { controls }\end{array}$ & $p$ value \\
\hline First third & & & \\
NREM1 & $1.4 \pm 1.1$ & $2.0 \pm 1.2$ & $<0.06$ \\
NREM2 & $3.7 \pm 1.2$ & $3.4 \pm 1.3$ & NS \\
SWS & $2.4 \pm 1.0$ & $2.0 \pm 0.6$ & NS \\
REM & $1.2 \pm 0.7$ & $0.6 \pm 0.7$ & $<0.01$ \\
Second third & & & \\
NREM1 & $1.2 \pm 1.5$ & $1.3 \pm 1.1$ & NS \\
NREM2 & $3.7 \pm 1.2$ & $3.4 \pm 1.3$ & NS \\
SWS & $0.8 \pm 0.6$ & $1.1 \pm 0.6$ & NS \\
REM & $1.6 \pm 0.7$ & $2.0 \pm 0.7$ & $<0.05$ \\
Third third & & & \\
NREM1 & $1.4 \pm 1.5$ & $0.9 \pm 0.9$ & NS \\
NREM2 & $3.0 \pm 1.1$ & $3.0 \pm 1.1$ & NS \\
SWS & $0.8 \pm 0.7$ & $1.0 \pm 0.7$ & NS \\
REM & $2.6 \pm 0.8$ & $2.2 \pm 0.8$ & $<0.07$ \\
\hline
\end{tabular}

$*$ Values are means $\pm \mathrm{SD}$.

Table 5. REM sleep and NREM sleep stages episode duration (min) for each third of the TST

\begin{tabular}{cccc}
\hline & Former IDA & $\begin{array}{c}\text { Nonanemic } \\
\text { controls }\end{array}$ & $p$ value \\
\hline First third & & & \\
NREM1 & $6.0 \pm 6.3$ & $5.3 \pm 3.3$ & NS \\
NREM2 & $22.3 \pm 10.9$ & $21.2 \pm 9.3$ & NS \\
SWS & $32.0 \pm 15.1$ & $30.0 \pm 5.6$ & NS \\
REM & $15.6 \pm 9$ & $7.7 \pm 5.6$ & $<0.007$ \\
Second third & & & \\
NREM1 & $7.2 \pm 3.6$ & $4.8 \pm 3.3$ & $<0.02$ \\
NREM2 & $32.7 \pm 18.3$ & $32.0 \pm 13.5$ & NS \\
SWS & $24.0 \pm 11.0$ & $20.3 \pm 8.0$ & NS \\
REM & $19.8 \pm 12.5$ & $15.6 \pm 6.0$ & NS \\
Third third & & & \\
NREM1 & $7.8 \pm 5.9$ & $5.6 \pm 3.3$ & NS \\
NREM2 & $35.3 \pm 21.2$ & $32.0 \pm 10.5$ & NS \\
SWS & $18.8 \pm 12.8$ & $18.6 \pm 11.0$ & NS \\
REM & $11.6 \pm 4.2$ & $21.3 \pm 9.0$ & $<0.0001$ \\
\hline
\end{tabular}

* Values are means $\pm \mathrm{SD}$.
Table 6. First sleep cycle features

\begin{tabular}{lccc}
\hline & Former IDA & $\begin{array}{c}\text { Nonanemic } \\
\text { controls }\end{array}$ & $p$ value \\
\hline REM latency (min) & $111.3 \pm 42.5$ & $149.7 \pm 38.3$ & $<0.002$ \\
REM episode duration (min) & $15.0 \pm 10.4$ & $10.7 \pm 7.2$ & $<0.07$ \\
NREM sleep stages duration & & & \\
$\quad$ NREM1 (min) & $6.4 \pm 6.8$ & $6.3 \pm 6.2$ & NS \\
NREM2 (min) & $31.8 \pm 26.4$ & $48.8 \pm 22.1$ & $<0.02$ \\
SWS (min) & $58.9 \pm 27.8$ & $72.6 \pm 20.4$ & $<0.03$ \\
\hline * Values are means \pm SD. & & &
\end{tabular}

children. The number of control and former IDA children who napped was similar -5 out of 28 and 6 out of 27, respectively.

Sleep organization during the first third of the TST. Within the first third of the TST, the percentage of REM sleep was higher in the former IDA group compared with the control group $(3.1 \pm 2.4$ versus $1.3 \pm 1.8, p<0.006)$. The difference was due to both a longer duration of episodes (15.6 \pm 9.6 versus $7.7 \pm 5.6 \mathrm{~min}, p<0.007)$ and a higher number of them $(1.2 \pm 0.7$ versus $0.6 \pm 0.7, p<0.01)$. The percentage of NREM stages was similar in both groups. However, when the first sleep cycle was evaluated separately, former IDA children showed shorter durations of NREM2 (31.8 \pm 26.4 versus $48.8 \pm 22.1 \mathrm{~min}, p<0.02)$ and SWS $(60.6 \pm 27$ versus $75.5 \pm$ 20 min, $p<0.03)$ episodes, shorter REM latency $(111.3 \pm$ 42.5 versus $149.7 \pm 38.3 \mathrm{~min}, p<0.002)$ and a suggestive tendency for longer duration of the REM episode $(15.0 \pm 10.4$ versus $10.7+7.2 \mathrm{~min}, p<0.07)$ relative to control children.

Sleep organization during the second third of the TST. Within the second third of the night, the number of REM episodes was lower in the former IDA group than in the control group $(1.6 \pm 0.7$ versus $2.0 \pm 0.7, p<0.05)$ and the duration of NREM1 episodes was longer ( $7.2 \pm 3.6$ versus $4.8 \pm$ 3.3 min, $p<0.02$ ).

Sleep organization during the last third of the TST. Within the last third of the TST, the percentage of REM sleep was lower in former IDA children compared with controls (6.9 \pm 2.8 versus $9.8 \pm 4.0, p<0.002)$. This was due to shorter episodes $(11.6 \pm 4.2$ versus $21.3 \pm 9.0 \mathrm{~min}, p<0.0000)$, because, if anything, former IDA children had a higher number of episodes $(2.6 \pm 0.8$ versus $2.2 \pm 0.8, p<0.07)$.

\section{DISCUSSION}

This study indicated that, despite adequate iron therapy in infancy, 4-y-old children who had IDA in infancy showed altered sleep organization throughout the night. The pattern of REM sleep episode duration in controls showed the expected lengthening with advancing thirds of the night. In contrast, former IDA children did not. Instead, compared with controls, the duration of their REM sleep episodes was longer in the first third and shorter in the last third of the night. The timing of REM sleep episodes also differed between groups. Former IDA children showed a higher number of REM sleep episodes, significant in the first third and a suggestive tendency in the third, whereas they showed fewer REM sleep episodes in the second third. In addition, the first sleep cycle in former IDA children differed markedly relative to controls: the latency to 
the first REM sleep episode was shorter, the episode tended to be longer, and the episodes of NREM2 and SWS were shorter.

One possible explanation for the differences could be the higher proportion of males in the former IDA group. At age 4-6 y, boys have been observed to sleep longer and spend more time in NREM2 than girls (17). Since we used gender as a covariate in all statistical comparisons, this factor is unlikely to explain the differences in sleep characteristics between former IDA and control children. Another factor might be daytime sleep, which exerts a strong inhibitory effect on the expression of SWS in the subsequent night $(18,19)$. The longer duration of the prior waking episode in the former IDA group would usually be associated with increased SWS amount at the onset of the sleep episode, instead of the decreased SWS we observed. This appears to make it unlikely that differences in daytime sleep and waking account for the findings. However, the REM sleep rebound effect is a slower mechanism than the increased SWS after sleep deprivation. Therefore, the longer duration of the prior daytime waking episode in the IDA children could contribute to an increased REM sleep pressure and, hence, more REM sleep in the first part of the night.

An additional explanation could be differing amounts of sleep alterations. In particular, restless legs syndrome and periodic limb movements during sleep have been associated with conditions characterized by compromised iron status (20-24). Even though this aspect was outside the scope of the current study, our results do not seem to point in this direction. Sleep alterations related to such leg movement disorders are characterized by disturbed sleep onset and/or maintenance (20), whereas the groups in our study showed similar sleep latency and WASO was smaller in the former IDA group.

Some characteristics of REM sleep organization in formerly IDA children might be an expression of a slower developmental profile of this state. The pattern and distribution of REM sleep change and its recurrence time throughout the night typically lengthens as children get older (25-27). Regarding the altered REM features in former IDA children, the results might also be relevant to the increase in symptoms of anxiety and depression reported in young adolescents who had chronic, severe iron deficiency in infancy (28). Our findings of shorter latency and prolonged duration of the first episode and absence of progressive lengthening of episodes duration with advancing sleep period are reminiscent of REM sleep patterns often observed in depressive patients (29).

The mechanisms by which IDA in infancy could result in long-lasting changes in sleep state organization are unknown. However, it is possible that they relate to brain processes in which iron plays an important role. Long-lasting effects of iron deficiency on the developing dopamine (DA) system are a promising example $(2,8,9,12,15)$. Neuromodulation by the DA system plays an important role in sleep regulation (30), including the modulation of REM sleep quality, quantity, and timing $(31,32)$. Furthermore, IDA alters DA neurotransmission in specific areas of the brain, among which are those critically involved in sleep regulation $(33,34)$. For instance, the basal ganglia become high in iron concentration and are more highly interconnected with REM-regulatory structures in the mesopontine tegmentum than with any other brain region $(35,36)$. Some changes induced by early iron deficiency in the basal ganglia are not corrected with iron supplementation $(2,8,9,37)$.

The dynamic balance between neurotransmitter systems is another important consideration. The ultradian alternation of NREM sleep/REM sleep appears to be controlled by a permanent interacting balance between brainstem aminergic and cholinergic neuronal discharges $(33,34)$. Relevant to this issue are findings in recent iron deficiency studies in rodent models showing alterations not only in the DA system but also central serotonin and noradrenergic transporters and levels $(8,9,37)$. Since only some of the changes were reversible by iron supplementation at weaning $(8,9,37)$, the resulting IDAinduced neurotransmission imbalance could affect the finegraded neural mechanisms involved in the regulation of sleep states patterning.

In addition, a recently described model involves reciprocal inhibitory interactions between brainstem gamma-aminobutyric acid (GABA)-ergic REM-off and REM-on populations as main components of the REM switch (38). Since iron deficiency may also affect GABA-ergic transmission systems (39), the ongoing balance between the GABA-ergic populations may be altered as well, contributing to the altered transitions into and out of REM sleep observed in former IDA children.

Early alterations in DA pathways exert persistent effects on context-dependent affective responses and cognitive functioning (40). Altered responses to novel stimuli and settings have been observed in the IDA rodent model and are suggested in human infants by increased wariness/hesitance (reviewed in ref. 2) and differences between laboratory and home environments in motor activity (6). However, if former IDA children were particularly affected by the novel environment and procedures, their sleep patterns would probably be different from those we observed, since the so-called first night effect is mainly characterized by longer REM latency, less total sleep time, and less REM sleep, with more intermittent awake time, and lower sleep efficiency $(41,42)$.

Another consideration is iron's role in normal myelination. Disruptions in iron processing, storage, or availability affect myelin quantity, quality, composition, and compaction $(43,44)$, with alterations that persist even if the iron content of the myelin achieves normal levels after iron supplementation (45). As suggested previously in the same sample (4), the slower transmission in both auditory and visual systems likely arises from iron's role in myelination. It is reasonable to postulate that the effects of iron deficiency on myelination might decrease the efficiency of neural signalling not only in sensory systems but also in those involved in the circuitry of sleep regulation.

This study was limited in several ways: a) A single night recording in the laboratory may alter sleep organization in some children more than others, and additional nights would be needed to evaluate this issue. b) Bedtime and sleep onset were determined following the individual child's routines. Although this may seem more open to uncontrolled factors, we considered it important to increase the children's comfort by respecting the usual timing of sleep. However, the ap- 
proach introduced more variability in the time of going to bed and falling asleep. c) Since we did not assess REM sleep in its tonic and phasic stages (46), we could not estimate the contribution of each REM sleep stage to differences between the groups. Future studies of these relations might help clarify our results. d) We did not assess daytime sleepiness and thus cannot determine whether disrupted nighttime sleep adversely affected waking tone. e) Underlying mechanisms could not be determined in a study like this. Further research, most probably in animal models, is clearly required to elucidate them.

In conclusion, altered temporal organization of sleep patterns in otherwise healthy former IDA children indicate that iron plays a role in the normal progression and establishment of sleep patterning. Our results also suggest that early IDA is associated with lasting alterations in key components of functional integration and brain development that derail the temporal modulation of sleep organization. Sustained alteration in sleep organization for whatever reason may have negative consequences for development. Thus, altered sleep features may represent a fundamental process that interferes with optimal functioning during sleep and wakefulness in former IDA children.

Acknowledgments. The authors thank the children and parents whose ongoing participation made this study possible. We also thank Miriam Dinamarca for valuable assistance, all technicians who performed night recordings during the course of this study, and drivers for providing careful transportation services to children and parents.

\section{REFERENCES}

1. Lozoff B, De Andraca I, Castillo M, Smith JB, Walter T, Pino P 2003 Behavioral and developmental effects of preventing iron-deficiency anemia in healthy full-term infants. Pediatrics 112:846-854

2. Lozoff B, Beard J, Connor J, Felt B, Georgieff M, Schallert T 2006 Long-lasting neural and behavioral effects of iron deficiency in infancy. Nutr Rev 64:S34-S43

3. Roncagliolo M, Garrido M, Walter T, Peirano P, Lozoff B 1998 Evidence of altered central nervous system development in young iron deficient anemic infants: delayed maturation of auditory brainstem responses. Am J Clin Nutr 68:683-690

4. Algarín C, Peirano P, Garrido M, Pizarro F, Lozoff B 2003 Iron deficiency anemia in infancy: long-lasting effects on auditory and visual system functioning. Pediatr Res 53:217-223

5. Angulo-Kinzler RM, Peirano P, Lin E, Garrido M, Lozoff B 2002 Spontaneous motor activity in human infants with iron-deficiency anemia. Early Hum Dev 66:67-79

6. Angulo-Kinzler RM, Peirano P, Lin E, Algarín C, Garrido M, Lozoff B 2002 Twenty-four-hour motor activity in human infants with and without iron-deficiency anemia. Early Hum Dev 70:85-101

7. Grantham-McGregor S, Ani C A review of studies on the effect of iron deficiency on cognitive development in children. J Nutr 2001;131:649S-666S

8. Beard JL, Felt B, Schallert T, Burhans M, Connor JR, Georgieff MK 2006 Moderate iron deficiency in infancy: biology and behavior in young rats. Behav Brain Res 170:224-232

9. Felt BT, Beard JL, Schallert T, Shao J, Aldridge JW, Connor JR, Georgieff MK, Lozoff B 2006 Persistent neurochemical and behavioral abnormalities in adulthood despite early iron supplementation for perinatal iron deficiency anemia in rats. Behav Brain Res 171:261-270

10. Fallone G, Owens JA, Deane J 2002 Sleepiness in children and adolescents: clinical implications. Sleep Med Rev 6:287-306

11. O'Brien LM, Gozal D 2004 Neurocognitive dysfunction and sleep in children: from human to rodent. Pediatr Clin North Am 51:187-202

12. Beard JL, Erikson KM, Jones BC 2002 Neurobehavioral analysis of developmental iron deficiency in rats. Behav Brain Res 134:517-524

13. Hunt JR, Zito CA, Erjavec J, Johnson LK 1994 Severe or marginal iron deficiency affects spontaneous physical activity in rats. Am J Clin Nutr 59:413-418
14. Glover J, Jacobs A 1972 Activity pattern of iron-deficient rats. BMJ 2:627-628

15. Youdim MB, Yehuda S, Ben-Uriah Y 1981 Iron deficiency-induced circadian rhythm reversal of dopaminergic mediated behaviours and thermoregulation in rats. Eur J Pharmacol 74:295-301

16. Rechtschaffen A, Kales A 1968 A Manual of Standardized Terminology, Techniques, and Scoring Systems for Sleep Stages of Human Subjects. UCLA, Brain Research Institute/Brain Information Service, Los Angeles, CA

17. Kahn E, Fisher C, Edwards A, Davis DM 1973 24-hour sleep patterns. A comparison between 2- to 3-year-old and 4- to 6-year-old children. Arch Gen Psychiatry 29:380-385

18. Karacan I, Williams RL, Finley WW, Hursch CJ 1970 The effects of naps on nocturnal sleep: influence on the need for stage-1 REM and stage 4 sleep. Biol Psychiatry 2:391-399

19. Feinberg I, March JD, Floyd TC, Jimison R, Bossom-Demitrack L, Katz PH 1985 Homeostatic changes during post-nap sleep maintain baseline levels of delta EEG. Electroencephalogr Clin Neurophysiol 61:134-137

20. Trenkwalder C, Paulus W, Walters AS 2005 The restless legs syndrome. Lancet Neurol 4:465-475

21. Earley CJ, Allen RP, Beard JL, Connor JR 2000 Insight into the pathophysiology of restless legs syndrome. J Neurosci Res 62:623-628

22. Simakajornboon N, Gozal D, Vlasic V, Mack C, Sharon D, McGinley BM 2003 Periodic limb movements in sleep and iron status in children. Sleep 26:735-738

23. Allen R 2004 Dopamine and iron in the pathophysiology of restless legs syndrome (RLS). Sleep Med 5:385-391

24. Allen RP 2007 Controversies and challenges in defining the etiology and pathophysiology of Restless Legs Syndrome. Am J Med 120:S13-S21

25. Roffwarg HP, Muzio JN, Dement WC 1966 Ontogenetic development of the human sleep-dream cycle. Science 152:604-619

26. Bes F, Schulz H, Navelet Y, Salzarulo P 1991 The distribution of slow-wave sleep across the night: a comparison for infants, children, and adults. Sleep 14:5-12

27. Peirano P, Algarín C, Uauy R 2003 Sleep-wake states and their regulatory mechanisms throughout early human development. J Pediatr 143:S70-S79

28. Lozoff B, Jimenez E, Hagen J, Mollen E, Wolf AW 2000 Poorer behavioral and developmental outcome more than 10 years after treatment for iron deficiency in infancy. Pediatrics 105:E51

29. Benca RM, Obermeyer WH, Thistead RA, Gillin JC 1992 Sleep and psychiatric disorders: a meta-analysis. Arch Gen Psychiatry 49:651-668

30. Dzirasa K, Ribeiro S, Costa S, Santos LM, Lin S-C, Grosmark A, Sotnikova TD, Gainetdinov RR, Caron MG, Nicolelis MA 2006 Dopaminergic control of sleepwake status. J Neurosci 26:10577-10589

31. Keating GL, Rye DB 2003 Where you least expect it: dopamine in the pons and modulation of sleep and REM-sleep. Sleep 26:788-789

32. Crochet S, Sakai K 2003 Dopaminergic modulation of behavioural states in mesopontine tegmentum: a reverse microdialysis study in freely moving cats. Sleep 26:801-806

33. Pace-Schott EF, Hobson JA 2002 The neurobiology of sleep: genetics, cellular physiology and subcortical networks. Nat Rev Neurosci 3:591-605

34. McCarley RW 2004 Mechanisms and models of REM sleep control. Arch Ital Biol 142:429-467

35. Rye DB 1997 Contributions of the pedunculopontine region to normal and altered REM sleep. Sleep 20:757-788

36. Mena-Segovia J, Bolam JP, Magill PJ 2004 Pedunculopontine nucleus and basa ganglia: distant relatives or part of the same family? Trends Neurosci 27:585-588

37. Burhans MS, Dailey C, Beard Z, Wiesinger J, Murray-Kolb L, Jones BC, Beard JL 2005 Iron deficiency: differential effects on monoamine transporters. Nutr Neurosci 8:31-38

38. Lu J, Sherman D, Devor M, Saper CB 2006 A putative flip-flop switch for control of REM sleep. Nature 441:589-594

39. Rao R, Tkac I, Townsend EL, Gruetter R, Georgieff MK 2003 Perinatal iron deficiency alters the neurochemical profile of the developing rat hippocampus. J Nutr 133:3215-3221

40. Schallert T, Petrie BF, Whishaw IQ 1989 Neonatal dopamine depletion: spared and unspared sensorimotor and attentional disorders and effects of further depletion in adulthood. Psychobiology 17:386-396

41. Scholle S, Scholle HC, Kemper A, Glaser S, Rieger B, Kemper G, Zwacka G 2003 First night effect in children and adolescents undergoing polysomnography for sleep-disordered breathing. Clin Neurophysiol 114:2138-2145

42. Verhulst SL, Schrauwen N, De Backer WA, Desager KN 2006 First night effect for polysomnographic data in children and adolescents with suspected sleep disordered breathing. Arch Dis Child 91:233-237

43. Kwik-Uribe CL, Gietzen D, German JB, Golub MS, Keen CL 2000 Chronic marginal iron intakes during early development in mice result in persistent changes in dopamine metabolism and myelin composition. J Nutr 130:2821-2830

44. Beard JL, Wiesinger JA, Connor JR 2003 Pre- and postweaning iron deficiency alters myelination in Sprague-Dawley rats. Dev Neurosci 25:308-315

45. Ortiz E, Pasquini JM, Thompson K, Felt B, Butkus G, Beard J, Connor JR 2004 Effect of manipulation of iron storage, transport, or availability on myelin composition and brain iron content in three different animal models. J Neurosci Res 77:681-689

46. Takahashi K 1999 Intensity of REM Sleep. In: Mallick BN, Inoue S (eds) Rapid Eye Movement Sleep. Marcel Dekker, New York, pp 382-392 